\title{
The effect of information feedback in construction bidding
}

Alexander Soo and Bee Lan Oo (School of Civil Engineering, University of Sydney)

\begin{abstract}
With the goal to achieve efficiency in bidding competitions, many codes of bidding procedure recommend clients provide contractors with bidding feedback information. Contractors strive to bid competitively via learning based on their experiences in past bidding attempts. The level of bidding feedback information, however, varies across clients. In many cases, clients do not provide feedback or provide insufficient feedback to contractors. Focussing on two information feedback conditions (full and partial), we examine: (i) the changes in bidding trend over time, and (ii) the effects of bidding feedback information on bidders' competitiveness in bidding. Data were gathered using a bidding experiment that involved student (inexperienced) bidders with a construction project management background. The results show that the variations in bids over time for full information feedback condition are statistically significant, but not for bids from bidders with partial bidding feedback information. Bidders with full bidding feedback information are more competitive than those with partial bidding feedback information. The findings add to both our theoretical and empirical understanding of construction bidding: an understanding of the process of changes in the price of building work, and how the process can be manipulated through the release of bidding feedback information.
\end{abstract}

Keywords: Bidding, Construction, Experiment, Feedback.

\section{Introduction}

Construction clients' objective of awarding a contract is to agree upon a contract type and price that produces reasonable risk and maximises the incentive for efficient and economic performance of a contractor (Kerzner 2006). They will naturally aim to strike the best bargain by introducing some kind of competition, by some form of negotiation or by a mixture of the two. Descending first-price sealed-bid auctions are most commonly used in the industry where competing contractors submit independent bids (i.e., offers to sell construction services) and the lowest bidder wins at the lowest bid price. The competitive bidding is the driving force for contractors providing lower bid prices to suit the clients' construction and financial needs (Drew and Skitmore 1992). Nonetheless, Runeson (2000) noted that a bid offer must be equal to or above the minimum price at which a contractor is prepared to undertake also considering acceptable probability of profit without an unacceptable risk of loss.

Contractors adopt various strategies to enhance their chances of winning projects. Their experiences in past bidding competitions play a role in offering competitive bid prices. Using bidding data of building projects, Fu et al. (2004) found that experienced bidders who bid frequently are more competitive than bidders who bid occasionally, where experiential learning in recurrent bidding plays a key role. In this, bidding feedback information is necessary to facilitate contractors' learning (Kagel and Levin 2002). Varying information feedback conditions have been shown to affect a bidder's competitiveness to different degrees in sealed-bid auctions, whereby affecting the revenues for those accepting bids to 
buy or accepting offers to sell (e.g. Issac and Walker 1985; Dufwenberg and Gneezy 2002; Engelbrecht-Wiggans and Katok 2008).

Many codes of bidding procedure recommend clients provide contractors with bidding feedback information (e.g. New South Wales Government 2005; Ministry of Finance 2005). The level of bidding feedback information, however, varies across clients. For example, while the Singapore Government releases the full list of bidders and their bids on the GeBIZ government website (www.gebiz.gov.sg), the New South Wales Government in Australia releases the details of successful bid only (www.tenders.nsw.gov.au). In many cases, clients do not provide feedback or provide insufficient feedback to contractors (Drew and Fellows 1996). Although their survey respondents indicated that they obtain bidding data from a variety of sources, including: competitors, subcontractors, friendly acquaintances, suppliers and newspapers, little is known about the effects of varying levels of bidding feedback information on construction bid prices. This study aims to examine the effects of two information feedback conditions in construction bidding. Using an experimental approach, two groups of inexperienced bidders were randomly allocated to full and partial information feedback conditions, respectively. With regard to the two information feedback conditions, the specific objectives are to examine: (i) the changes in bidding trend over time, and (ii) the effects of bidding feedback information on bidders' competitiveness in bidding. The study provides an insight into changes in the price of building work associated with the release of bidding feedback information.

\section{Effects of Information in Construction Bidding}

Information related to construction bidding can be separated into two categories, namely public information and feedback information. Public information, as the name implies, refers to information that is publicly available such as project type and size, project location and client identity. Feedback information refers to the information provided at the end of bidding competitions. Depending on clients' procurement procedure, the levels of bidding feedback information given to contractors varies. Drew and Fellows (1996) identified that contractors use bidding feedback information for four different purposes: (i) for deciding on whether or not to bid for future projects, (ii) for determining mark-up for future projects, (iii) for analysing their bidding performance; and (iv) for analysing bidding performance of their competitors.

\section{Public Information}

There have been many studies on the effects of public information in competitive bidding. The leading article referenced by many authors appears to be that written by Milgrom and Weber (1982). They define public information being either a cost estimate provided by the client or project information such as geological data or proprietary information (private surveys, etc). In ascending first-price sealed-bid auctions (i.e., highest bidder wins at the highest bid price), they found that bidders bid more aggressively when public information is released, hence raising the seller's profit. In another study by de Silva et al. (2008), which examined the impact of public information on highway procurement where lowest bidder wins the job, they found that the release of a cost estimate on bridge procurement projects led to a sharp decrease in the bids received. The adjustment in bid prices from what is believed to be a more accurate cost estimate from the procurement agency suggests that bidders have a strong intent on winning the bid, and lowering the bid increases their chances of winning. These studies suggest greater revenues for those agents accepting bids or accepting offers. However, a recent study by de Silva et al. (2009) detected that bidders typically bid higher on procurement contracts from the Oklahoma Department of Transportation, following the release of cost estimate from the procurement agency which allowed them to readjust their bids in order to gain a higher profit margin.

\section{Feed back Information}

The effects of varying information feedback conditions on bidders' bidding behaviour have been identified via experimental setting in conventional economics literature. These

Soo, A and Oo, B L (2010) 'The effect of information feedback in construction bidding', Australasian Journal of Construction Economics and Building, 10 (1/2) 65-75 
experiments were designed in two main settings, namely ascending first-price sealed-bid auction and descending first-price sealed-bid auction. In ascending first-price sealed-bid auctions, Engelbrecht-Wiggans and Katok (2008) conducted an experiment that involved student subjects to bid for a fictitious asset in 100 auctions. They found that revealing the winning bids led to a higher average bid, and that the critical feedback information is the winning bids, as other information feedback condition (full information about past bids) appears to exhibit variability (either an increasing or decreasing trend) in the student subjects' bids. Similarly, Neugebauer and Perote (2008) detected that the release of winning bid triggers bidders in their experiment to base their bids on the winning bid, as opposed to a no information feedback condition where they must rely on their experiences through recurrent bidding. They found that the release of feedback information led to higher overall bids. Neugebauer and Selten (2006) have also detected overbidding in partial information feedback condition that lead to generally higher bids among subjects in their experiment that aimed to examine the effects of partial and no information feedback conditions on bidders' behaviour. Another experiment by Issac and Walker (1985), however, shows that full information feedback condition produces lower bid prices in comparing the effects of full (all past bid) and partial (winning bid) information feedback conditions among naïve bidders in an ascending sealed-bid auction. In another study by Ockenfels and Selten (2005), they found that a no information feedback condition generally leads to higher bids in an ascending sealed-bid auction. Their research involved observing the upward and downward impulses of bidding subjects. The weighted impulse is defined in their research as a mix of winning utility and risk aversion strategies. They noted that bidding subjects with no feedback information were unable to consider the relative sizes of the downward and upward impulses and systematically underestimate the downward impulses leading to higher bids.

In a descending first-price sealed-bid auction, Dufwenberg and Gneezy (2002) studied the effects of various information feedback conditions on bidders' behaviour (i.e., revealing all bids, all winning bids or no bids) for ten rounds. They found that the condition where full bidding feedback information was provided led to much higher bid prices over the limited and no information feedback conditions, thereby raising the seller's profit. Their results also show that information released about a bidder's own performance generally leads to a lower bid, which is in line with Engelbrecht-Wiggans and Katok's (2008) finding that the winning price is the most critical feedback information. Moving towards a modelling attempt on feedback information in descending first-price auctions, Esponda (2008) suggests that the release of feedback information leads to an incorrect evaluation by bidders due to overestimation of the expected profit from the past bids. His empirical analysis shows that the feedback information does have a correlation to bid prices.

Although the effects of different information feedback conditions on bidders' behaviour seem to be mixed in the above experimental studies, it is clear that the experiment subjects had used the feedback information, to varying degree, for analysing the bidding performance of competing bidders. This would allow for insight into competitors' bidding trends or movements (Friedman 1956). The information gained could be used to estimate the probable range of competitors' bids (Milgrom 1989), and to differentiate the less serious competitors from the more serious (McCaffer 1976). Kortanek et al. (1973) noted that a bidder's bidding strategy which reflects its bidding behaviour at any time is a direct product of learning, governing the bidder's competitiveness.

\section{Bidding trends over time}

Much has been reported on variations in bids over time, suggesting that price differences originate in systematic variations rather than random variations (e.g. de Neufville et al. 1977, Flanagan and Norman 1985, Chan et al. 1996). Runeson and Skitmore (1999) argued that variations in bids over time can be explained by changes in demand, firm capacity level and competitor behaviour. Highly correlated with changes in demand is the bidders' need for work, which tends to be high in recession time as demand decreases. As demonstrated by

Soo, A and Oo, B L (2010) 'The effect of information feedback in construction bidding', Australasian Journal of Construction Economics and Building, 10 (1/2) 65-75 
McCaffer and Pettitt's (1976) cusum curve, bidders typically reduce their bids gradually, relative to their competitors, until they win a contract. The attainment of the contract leads to a sharp increase in the subsequent bids by the bidders as they were not so eager to win a job. In their analysis using around 600 contracts involving about 400 contractors, it appears that there is a continuous cycle of upward and downward bidding trends over time. However, in a further study by Skitmore and Runeson (2006) that aimed at testing the statistical significance of the bidding trends detected in McCaffer and Pettitt (1976), they found that: (i) winning bids are not in general preceded by increasingly more competitive bids, and (ii) the trend of high and low bids over a period of time is most likely due to the presence of highly uncompetitive bids or outliers, for their dataset comprised bids from eight bidders. In yet another paper, Oo and Lo (2010) have identified the specific types of bidding trends before and after a winning bid using the longest series of bids from 67 bidders. Their model parameter estimates support the upward and downward trends before and after a winning bid in McCaffer and Pettitt's cusum curve (1976).

Here, we are concerned with changes in bidders' pricing behaviour over time in response to two information feedback conditions. As Runeson and Skitmore (1999) conjecture, the assumption that competing bidders do not modify their behaviour at any time (i.e., no allowance for continuity) is unlikely to be valid. The strategic motivation for changes in pricing behaviour is the long-term survival of a firm (Skitmore and Smyth 2007). Many construction organizations feel they have to fight for survival (Skitmore et al. 2006), especially when demand levels lead to overcapacity, intensified competition or changing client needs (Skitmore and Smyth 2007). With this as a backdrop, contractors have to rely on effective pricing methods in order to translate potential business into reality. This inevitably involves effective utilisation of bidding feedback information towards winning jobs with high profit potential. This study follows the notion that information never has a negative value to the decision-maker (Milgrom and Weber 1982). At worst, irrelevant bidding feedback information can be ignored by the bidders. Based on the research aim and objectives, there are two hypotheses that form the foundation of empirical investigation in this paper:

\section{H1: Inexperienced bidders do change their pricing behaviour in response to a given set of bidding feedback information.}

H2: Inexperienced bidders with full bidding feedback information are more competitive than inexperienced bidders with limited bidding feedback information in their bidding attempts.

\section{Research Method}

An experimental approach was chosen as the most suitable method to test the effects of information feedback conditions in construction bidding. Given that there are so many possible factors affecting contractors' decision making in pricing - only an experimental research design would allow for manipulation of variable(s), something that would not have been possible using field data. The complete design characteristics that apply to the experiment presented next were detailed in Oo and Soo (2010).

The experiment involved final year undergraduate students with a construction project management background and were enrolled in a project procurement course. They were randomly split into two groups, one with full bidding feedback information (list of all bidders and their submitted bids), the other with partial bidding feedback information (winning bid and identity of winning bidder). The two primary groups were further split into five subgroups (4 students in each subgroup) to emulate a bidding competition of five competing bidders. It should be noted that the experiment was conducted in a controlled environment with an experiment coordinator ensuring that strictly no communication was allowed between the groups to prevent bidder collusion.

Soo, A and Oo, B L (2010) 'The effect of information feedback in construction bidding', Australasian Journal of Construction Economics and Building, 10 (1/2) 65-75 
The experiment was carried out for eight rounds (one round per week) where seven hypothetical projects were generated in each bidding round. All bidding feedback information (either partial or full) was provided at the beginning of each bidding round. Within a timeframe of one hour, the subjects were required to decide which project to bid for, and the bid price if deciding to bid. The general instruction to the participants was that their ultimate aim was to survive and prosper, in a competition in which the lowest bidder wins the job, but how this can be achieved was left to them. This reflects the strategic nature of the construction pricing problem. The hypothetical projects were constructed using information from past real contracts obtained from the NSW e-tendering website. The projects selected were conventional buildings, such as schools and institutional buildings that involve usual design, and do not require any unusual construction technologies. This was done to control the effect of project type on bidders' bidding decisions. Apart from the project information (location, duration, client and contract type), the subjects were also given an unbiased cost estimate for each hypothetical project, which is the net project construction cost that includes the site overheads and project preliminaries (i.e., total of direct cost estimate + site overheads). Here, identical hypothetical projects were given to both the partial and full information feedback groups to enable direct comparison. In an attempt to make the experiment more realistic and to maintain subjects' interests over eight rounds, profit/loss was generated for each hypothetical project by deducting a randomly assigned final cost from the winning bid. The subject who generated the biggest profit at the end of eight rounds was declared the winner and received a mystery prize.

The main limitations of this experiment are that: (i) it is utilising students as experimental bidding subjects, and (ii) it does not consider other possible information feedback conditions. However, it is believed that the student subjects in the experiment have responded seriously since they asked the relevant questions after reading the instructions. In addition, the mystery prize for winning bidder was introduced as an incentive for the subjects to perform seriously in the experiment. In fact, the use of students in bidding experiments is a common approach to examine the effects of various bidding variables on bidders' bidding behavour (e.g. Dufwenberg and Gneezy 2002; Issac and Walker 1985; Neugebauer and Perote 2008). A study by Dyer et al. (1989) compared naïve (student) bidders against experienced (company executives) bidders in an experimental construction bidding environment. They found that there is no significant difference between the naïve and experienced bidders in terms of bidding performance. They did however note that naïve and experienced bidders differ in terms of their risk attitudes with naïve bidders being more risk aversive as opposed to risk neutral. With regards to the other limitation of other possible information feedback conditions, it is feasible to replicate the experiment with (i) no information feedback condition, and (ii) information feedback on winning bid only.

The data collected from this experiment was analysed using the Statistical Package for the Social Sciences (SPSS). The measure of competitiveness between bids is to express each bid as a ratio above the unbiased cost estimate, i.e., mark-up competitiveness ratio, MUCR = bidder's bid/unbiased cost estimate. The unbiased cost estimate provides a common baseline for comparison between the partial and full information feedback groups. A MUCR of 1 indicates that a bid is at the unbiased cost estimate (i.e., zero mark-up), and below 1 indicates a bidder has submitted a bid lower than the unbiased cost estimate that leads to a lower bid. Lower MUCR values indicate greater competitiveness since the lowest bidder wins at the lowest bid price. Consistency in bidding was then gauged from the resultant standard deviation.

\section{Results and Discussion}

The results are presented in three parts. The first part presents an exploratory analysis of bids obtained from both the partial and full information feedback groups. The competitiveness ratio (MUCR) was plotted against the corresponding bidding rounds to explore the differences in bidding trend between the two groups. The second part discusses

Soo, A and Oo, B L (2010) 'The effect of information feedback in construction bidding', Australasian Journal of Construction Economics and Building, 10 (1/2) 65-75 
the results of subseries analysis in detecting changes in bidding behaviour over time. The third part details the test results of the effects of bidding feedback information on the bidders' bidding competitiveness.

\section{Exploratory Analysis}

Table 1 shows the sample size for both the partial and full information feedback groups. For the partial information feedback group (i.e., Bidders A1 to A5), a total of 261 bids were obtained with the other 14 representing outliers or no-bid decisions. The full information feedback group (i.e., Bidders B1 to B5) provided 249 bids with 26 bids representing outliers and no-bid decisions. The removal of outliers was based on criterion set forth by the Hong Kong SAR government which considers all bids that are $25 \%$ above the lowest bid to be nonserious bids (Skitmore 2002). An one-sample Kolmogorov-Smirnov (K-S) test on the two data samples reveals a $p$-value less than 0.05 , indicating a violation of the assumption of normal distribution. Thus, non-parametric tests were used for subsequent testing of hypotheses.

\begin{tabular}{|l|c|c|c|c|c|c|}
\hline & \multicolumn{2}{|c|}{ Bid } & \multicolumn{2}{c|}{ No-bid/Outlier } & \multicolumn{2}{c|}{ Total } \\
\hline Feedback Conditions & N & Percent & N & Percent & N & Percent \\
\hline Partial Information & 261 & $94.9 \%$ & 14 & $5.1 \%$ & 275 & $100.0 \%$ \\
\hline Full Information & 249 & $90.5 \%$ & 26 & $9.5 \%$ & 275 & $100.0 \%$ \\
\hline
\end{tabular}

Table 1 Sample size for partial and full information feedback groups

For the exploratory analysis, scatter plots were used to display the spread of data for the partial and full information feedback groups as shown in Figures 1(a) and 1(b), respectively. LOWESS curves fitted to the scatter plots allow for bidding trends to be observed from the dataset. LOWESS stands for "LO"cally "WE"ighted "S"catter plot "S"moothing (Hardle 1990). The LOWESS fit line is based on local polynomial least squares fit to a set of data points. The fit is then "robustified" which is defined as resmoothing of the curve for several iterations to provide a more accurate trend representation of the dataset (Hardle,1990). The robustified LOWESS curve is more resistant to effects of noise and/or marginal outliers in any particular dataset. It can be seen that there is a steep decreasing trend in MUCR (i.e., more competitive bids) for the partial information feedback group from Round 1 to 2 . This can be considered as a learning curve adjustment. In this, with the winning bids revealed to all bidders, the bidders were able to assess their bids relative to the winning bids, and to review their performance and adjust their bidding strategies accordingly. However, from Round 3 onwards, the curve begins to stabilise, possibly representing the bidders' optimum bidding trend. It should be noted that the profit and loss statements provided to the bidders were not available until the end of Round 2 since the hypothetical projects have minimum project duration of two rounds. However, the feedback on profit/loss on winning bids did not trigger an immediate response in bidding trend. This observation is explained in Fu et al. (2004) where contractors becoming experienced through recurrent bidding and having obtained the optimal level of bidding strategy. Pawlowsky (2001) suggests that the steady state phase in bidding trend is because of the balance between the market forces and the knowledge of sustaining optimal bidding strategy. He advocates that a behavioural regularity is a symbol of best practices that were developed from a survival need to stay in the market and to make a profit. However, as Fu et al. (2004) pointed out, when the market forces change, learning occurs again and bidders will find alternative strategies to adapt to the new environment. This may explain the slight decreasing trend in MUCR for the last few rounds of the experiment for the partial information feedback group.

Soo, A and Oo, B L (2010) 'The effect of information feedback in construction bidding', Australasian Journal of Construction Economics and Building, 10 (1/2) 65-75 
(a) Partial information feedback group

(b) Full information feedback group
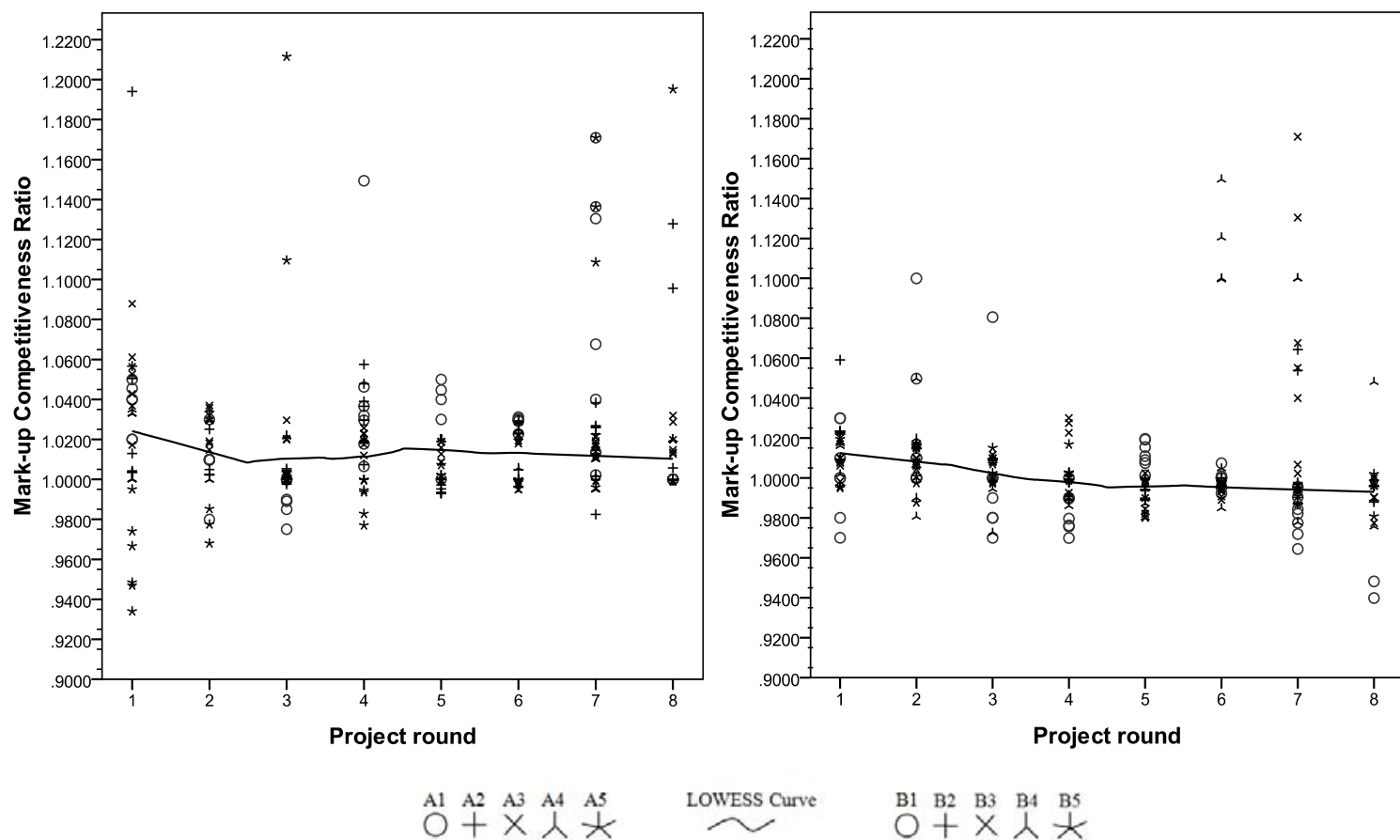

Figure 1 MUCR scatter plots for partial and full information feedback groups

For the full information feedback group, there is a continually decreasing trend in the MUCR, leading to generally lower bids. The LOWESS curve shows a fairly "flat" line, suggesting a consistent bidding trend among the five bidders. It appears that the full bidding feedback information throughout the experiment did not trigger an immediate response in bidding behaviour among the bidders. This could be due to the fact that the bidders had made full use of the bidding feedback information (identity and bids from all competing bidders) and were able to bid consistently and competitively. Another possible explanation for the rather consistent trend is that the extensive bidding feedback information retards the bidders' responses (learning) to new situations (Kagel and Levin 2002). The full information feedback group in the experiment have sufficient information to formulate their bidding strategies, and thus there is less reliance on experience and learning gained through recurrent bidding.

Comparing the two groups, it can be observed from the LOWESS curves that the full information feedback group bid more consistently and with lower overall bids compared to the partial bidding feedback information group. These are denoted by the LOWESS curves for partial information feedback group being above MUCR of 1 and the full information feedback group having the curve mostly below 1 . The latter suggests that Bidders B1 to B5 in full information feedback group had bid aggressively in general with tiny or even negative mark-ups (see Figure 1(b)). The amount of "kinks" in Figure 1(a) for the partial information feedback group also represents a lower bidding consistency, which is probably indicative of the adjustment in bidding strategies among Bidders A1 to A5.

\section{Changes in Bidding Trend}

The subseries analysis in Skitmore and Runeson (2006) was adopted here to test the hypothesis on changes in bidding trend over time. The disjointedness observed in the LOWESS curves over the eight bidding rounds was used as a basis to divide all bids for each information feedback group into subseries. A Friedman test was then applied to the multiple related subseries of bids for checking statistically significant differences in bidding trends. 
From the LOWESS curves in Figures 1(a) and 1(b), it can be seen that there are three disjointed trends for both the partial and full information feedback groups, indicating three subseries that comprised bids from Round 1 to 2,3 to 4 and 5 to 8 . The Round 2 disjoint could possibly be due to the release of profit and loss statements to the bidders' (triggering a behavioural response), however the Round 5 disjoint common to both information feedback conditions may be purely coincidental. The mean ranks of each subseries were then calculated, and the Chi-square values found in Friedman test are reported in Table 2. It should be noted that the mean rank is different to an arithmetic mean, and is an average of the MUCR rank with respect to the round subseries. A higher mean rank for a particular subseries indicates that the subseries has a higher MUCR overall. Consistent with the decreasing trends in LOWESS curves, the results show that the mean rank for Round 1 to 2 subseries is higher than the subsequent two subseries in both information feedback groups. However, it is clear that there is no statistically significant difference in MUCR for the three related subseries for the partial information feedback group $(p=0.403)$. Despite the "kinks" in the respective LOWESS curve, the results indicate that the variations in bids over time in response to the given set of partial bidding feedback information are statistically insignificant. This seemingly stable trend indicated by the respective mean rank can partly be explained because the bidders did not attempt "aggressive" manoeuvres such as bidding at or below the unbiased cost estimate (MUCR remained above 1.0 at all times).

In considering the full information feedback group, the results show that there are significant differences in MUCR across the three related subseries at the conventional 0.05 cut-off level. There is evidence to support that the bidders do modify their pricing behaviour based on the given set of full bidding feedback information. The respective mean rank indicates a rather steep decreasing trend in MUCR over the bidding periods, suggesting considerable changes in the bid price in terms of both frequency and magnitude. This observation is similar to that of Neugebauer and Selten (2006). They found that bidders adjusted their bids more frequently when they received clear information on their competitors' bids. Here, the hypothesis $\mathrm{H} 1$ which states that "inexperienced bidders do change their pricing behaviour systematically in response to a given set of bidding feedback information" is considered supported. It appears that learning does occur for both the partial and full information feedback groups but at different rates, with increasing accuracy and consistency in bid prices over the respective three subseries (i.e., decreasing differences in MUCR).

\begin{tabular}{|c|c|c|c|c|c|}
\hline Round Subseries & Mean Rank & $\mathbf{N}$ & Chi-Square & df & $p$ \\
\hline \multicolumn{6}{|c|}{ Partial information feedback group } \\
\hline $1-2$ & 2.133 & 60 & 1.816 & 2 & 0.403 \\
\hline $3-4$ & 1.975 & & & & \\
\hline $5-8$ & 1.892 & & & & \\
\hline \multicolumn{6}{|c|}{ Full information feedback group } \\
\hline $1-2$ & 2.542 & 59 & 27.526 & 2 & 0.000 \\
\hline $3-4$ & 1.822 & & & & \\
\hline $5-8$ & 1.636 & & & & \\
\hline
\end{tabular}

Table 2 Friedman test results for partial and full information feedlback groups

\section{The Effects of Information Feedlback Conditions on Bidding Competitiveness}

Table 3 shows the means of MUCR for the partial and full information feedback groups. It can be seen that the full information feedback group is more competitive on average with a lower mean MUCR compared to those in partial information feedback group. In addition, the standard deviation for the full information feedback group is lower, indicating a higher degree of consistency in their bidding attempts.

Soo, A and Oo, B L (2010) 'The effect of information feedback in construction bidding', Australasian Journal of Construction Economics and Building, 10 (1/2) 65-75 


\begin{tabular}{|l|c|c|c|}
\hline & N & Mean MUCR & Std. Deviation \\
\hline Partial Information & 261 & 1.0197 & 0.0361 \\
\hline Full Information & 249 & 1.0057 & 0.0284 \\
\hline
\end{tabular}

Table 3 Comparison of means of MUCR

To validate hypothesis $H 2$, a Mann-Whitney $U$ test was performed to test the difference in bidding competitiveness in terms of MUCR between the two groups. The results shows that the mean MUCR for full information feedback group is lower than the partial information feedback group at $p<0.05(U=19356.6 ; Z=-7.899 ; p=0.000)$. Hypothesis $H 2$ is thus supported where inexperienced bidders with full bidding feedback information are more competitive than those with partial bidding feedback information. This suggests that, in construction bidding, a full information feedback condition would lead to lower average bids. The conjecture to explain the findings is that comprehensive bidding feedback information opens up an "avenue" from which bidders may use the bidding data to inform their bidding decisions, and thus become more competitive and consistent in their bidding attempts. This conjecture is further supported by a paperback survey of the subjects with full bidding feedback information. The survey was allotted in every bidding round and the subjects were asked to indicate the usage of bidding data. For the eight bidding rounds there is a response rate of $90 \%$ whom had all indicated that they had utilised the bidding feedback information in formulating their bidding strategies and bid prices.

In examining the means of MUCR further, it is clear that the percentage mark-ups for both the partial and full information feedback groups are relatively low. While the partial information feedback group had a mean percentage mark-up of 1.97, a mean percentage mark-up as low as 0.57 was recorded for the full information feedback group. The general impression here is that the bidders had submitted bids with tiny or even negative mark-ups in the experiment, and that the resultant bids would likely result in a loss. In this case, the majority of the bidders in both groups recorded a loss at the end of experiment, with several instances of 'suicidal' bids that resulted in big losses. Although the phenomenon of submitting suicidal bids is not new in literature (e.g. Fellows and Langford 1980; Dyer and Kagel 1996), it would seem that the bidders' bidding behaviour in the experiment is affected by loss aversion to different degrees. However, the observed bidding trend shall not nullify the hypothesis testing results since the method of assigning final cost for the hypothetical projects is purely random.

\section{Conclusions}

This research examines the effects of information feedback conditions in construction bidding through an experimental setting, where two groups of inexperienced bidders were supplied with full and partial bidding feedback information, respectively. The results show that the variations in bids over time in response to a given set of full bidding feedback information are statistically significant, but not for bids from bidders with access to partial bidding feedback information. Hypothesis $H 1$ is thus considered partially supported. The test results for hypothesis $\mathrm{H} 2$ show that inexperienced bidders with full bidding data from previous bidding rounds are more competitive than those with partial bidding feedback information. The mean mark-up competitiveness ratio (i.e., bidder's bid/unbiased cost estimate) for the full information feedback group is 0.014 lower than the partial information feedback group. This suggests that full information feedback condition would lead to lower average bids in construction bidding. The findings add to both our theoretical and empirical understanding of construction bidding: an understanding of the process of changes in the price of building work, and how the process can be manipulated through the release of bidding feedback information. 
For construction clients, this study has demonstrated the need to consider the level of bidding feedback information in their formulation of procurement strategies. However, of the little empirical evidence in literature, further work is required to determine the point at which bidding feedback information can be regarded as 'sufficient' to aid efficiency in construction bidding. It may be possible to replicate this study by having experienced bidders as subjects to obtain empirical support on the extent to which contractors' bid pricing is affected by varying information feedback conditions, and thus to establish the external validity of the experiment. For further testing, an alternative would be to apply a statistical modelling technique, say, mixed effects model to provide estimation for bidding trends over time in response to different information feedback conditions

\section{Acknowledgements}

The authors would like to thank Raymond Loh for his assistance in experimental design as well as collecting the bidding data for the experiment.

\section{References}

Chan, SM, Runeson, G and Skitmore, M (1996) 'Changes in profit as market conditions change: An historical study of a building firm', Construction Management and Economics, 14(3), 253-264

De Neufville, R, Hani, EN and Lesage, Y (1977) 'Bidding models: effects of bidders' risk aversion', Journal of the Construction Division, ASCE, 103, 57-70

De Silva, DG, Dunne, T, Kankanamge, A and Kosmopoulou, G (2008) 'The impact of public information on bidding in highway procurement auctions', European Economic Review, 52 (1), 150-181

De Silva, DG, Kosmopoulou, G and Lamarche, C (2009) 'The effect of information on the bidding and survival of entrants in procurement auctions', Journal of Public Economics, 93 (1-2), 56-72

Drew, DS and Skitmore, M (1992) 'Competitiveness in bidding: a consultant's perspective', Construction Management and Economics, 10 (3), 227-247

Drew, DS, and Fellows, RF (1996) 'Feedback in construction contract bidding', Construction Modernization and Education: Proc., CIB Int. Conf., Oct 21-24, WP. Chang, ed., China Architectural \& Building Press, Beijing

Dufwenberg, M and Gneezy, U (2002) 'Information disclosure in auctions: an experiment', Journal of Economic Behavior and Organization, 48 (4), 431-444

Dyer, D, Kagel, JH and Levin, D (1989) 'A Comparison of Naive and Experienced Bidders in Common Value Offer Auctions - A Laboratory Analysis', Economic Journal, 99 (394), 108-15

Dyer, D and Kagel, JH (1996) 'Bidding in common value auctions: how the commercial construction industry corrects for the winners' curse', Management Science 42 (10), 14631475

Engelbrecht-Wiggans, R and Katok, E (2008) 'Regret and feedback information in first-price sealed-bid auctions', Management Science, 54 (4), 808-19

Esponda, I (2008) 'Information feedback in first price auctions', Rand Journal of Economics, 39 (2), 491-508

Fellows, RF and Langford, DA (1980) 'Decision theory and tendering', Building Technology and Management, Oct, 36-39

Flanagan, R and Norman, G (1985) 'Sealed bid auctions: an application to the building industry', Construction Management and Economics, 3 (2), 145- 61

Friedman, L (1956) 'A competitive bidding strategy', Operations Research, 4, 104-112

Soo, A and Oo, B L (2010) 'The effect of information feedback in construction bidding', Australasian Journal of Construction Economics and Building, 10 (1/2) 65-75 
Fu, WK, Drew, DS and Lo, HP (2004) 'Start-up and steady-state learning in recurrent bidding', Building Research and Information, 32 (6), 484-496. Hardle, W (1990) Applied Nonparametric Regression, Oxford University Press, Cambridge

Isaac, RM and Walker, JM (1985) 'Information and conspiracy in sealed bid auctions', Journal of Economic Behavior and Organization, 6 (2), 139-159

Kagel, JH and Levin, D (2002) Common Value Auctions and the Winner's Curse, Princeton University Press, New Jersey

Kerzner, H (2006) Project Management - a Systems Approach to Planning, Scheduling and Controlling, John Wiley \& Sons, New Jersey

Kortanek, KO, Soden, JV and Sodaro, D (1973) 'Profit analyses and sequential bid pricing models', Management Science Series A-Theory, 20 (3), 396-417

McCaffer, R (1976) Contractors' Bidding Behaviour and Tender Price Prediction, unpublished PhD thesis, Loughborough University of Technology

McCaffer, R and Pettitt, AN (1976) 'Bidding behaviour in project management', The Project Manager, 1 (5), 5-8

Milgrom, P (1989) 'Auctions and bidding - a primer', Journal of Economic Perspectives, 3 (3), 3-22

Milgrom, $\mathrm{P}$ and Weber, RJ (1982) 'The value of information in a sealed-bid auction', Journal of Mathematical Economics, 10(1), 105-114

Ministry of Finance (2005) Contracts and Purchasing Procedures, Ministry of Finance, Singapore

Neugebauer, T and Perote, J (2008) 'Bidding 'as if' risk neutral in experimental first price auctions without information feedback', Experimental Economics, 11 (2), 190-202

Neugebauer, T and Selten, R (2006) 'Individual behavior of first-price auctions: The importance of information feedback in computerized experimental markets', Games and Economic Behavior, 54 (1), 183-204

New South Wales Government (2005) Code of Practice for Procurement, New South Wales Government, Australia

Ockenfels, A and Selten, R (2005) 'Impulse balance equilibrium and feedback in first price auctions', Games and Economic Behavior, 51 (1), 155-170

Oo, BL and Lo, HP (2010) The effect of bidding success on contractors' bidding behaviour, Journal of Construction, Engineering and Management ASCE, (under review)

Oo, BL and Soo, A (2010) 'Bidding experiment: testing the effects of learning and information feedback in construction bidding', AUBEA 2010 Conference, Melbourne

Pawlowsky, P (2001) The treatment of organizational learning in management science. Handbook of Organizational Learning and Knowledge, Oxford University Press, New York

Runeson, G (2000) Building Economics, Deakin University Press, Geelong

Runeson, G and Skitmore, M (1999) 'Tendering theory revisited', Construction Management and Economics, 17 (3), 285-296

Skitmore, M (2002) 'Identifying non-competitive bids in construction contract auctions', Omega, 30 (6), 443-449

Skitmore, M and Runeson, G (2006) 'Bidding models: testing the stationarity assumption', Construction Management and Economics, 24 (8), 791-803

Skitmore, M and Smyth, HJ (2007) 'Pricing construction work: a marketing viewpoint', Construction Management and Economics, 25 (6), 619-630

Skitmore, RM Runeson, $G$ and Chang, X (2006) 'Construction price formation: full-cost pricing or neoclassical microeconomic theory?', Construction Management and Economics, 24 (7), 773-784

Soo, A and Oo, B L (2010) 'The effect of information feedback in construction bidding', Australasian Journal of Construction Economics and Building, 10 (1/2) 65-75 